\title{
Single Stage Aortic Arch Replacement without Circulatory Arrest
}

\author{
Ricardo G Marenchino, MD*, Alberto Domenech, MD \\ Cardiovascular Surgery Department, Hospital Italiano de Buenos Aires, Buenos Aires, Argentina
}

\begin{abstract}
A 78-year-old man with a Kommerell diverticulum and aberrant right subclavian artery was admitted for thoracic pain and severe malnutrition due to esophageal compression. We performed an atypical surgical procedure including extra-anatomical debranching and direct aortic repair, trying to avoid deep hypothermic circulatory arrest and shorten the cardiopulmonary bypass time.

Copyright $\odot 2016$ Science International Corp.
\end{abstract}

\section{Key Words}

\section{Kommerell diverticulum • Arch aneurysm repair}

\section{Introduction}

Aortic arch replacement under deep hypothermic circulatory arrest (DHCA) is a complex operation, associated with significant mortality and morbidity. The elderly and patients with poor physiologic reserve are often not candidates for these procedures. We describe a proposed technique for aortic arch replacement and the resection of a Kommerell diverticulum (KD) without DHCA in a frail and malnourished patient.

\section{Case Presentation}

A 78-year-old man with history of hypertension and renal insufficiency presented with back pain and severe dysphagia, which rendered the patient severely malnourished. The patient's body mass index was 15.7. The creatinine level was $1.3 \mathrm{mg} / \mathrm{dl}$, and the urea level was $108 \mathrm{mg} / \mathrm{dl}$. Computed tomography demonstrated an arch and proximal descending aortic aneurysm, measuring up to $12 \mathrm{~cm}$ in diameter. The left subclavian artery (LSA) and an aberrant right subclavian artery (ARSA) both arose from the distal aspect of the aneurysm. The proximal ARSA measured $70 \mathrm{~mm}$ in diameter, compressing the esophagus and displacing the trachea. Coronary angiography was normal; echocardiography showed normal ventricular function, the aortic valve was mildly calcified without gradient or insufficiency. There was no mitral regurgitation.

Not only was the intervention necessary to prevent rupture, but correction of the esophageal compression was also critical. Due to patient's debilitated state and co-morbidities we conceived this alternative surgical approach, which would avoid DHCA and shorten cardiopulmonary bypass (CPB) time while resolving the problem.

\section{Surgical Technique}

Access to the chest was obtained via a four intercostal space-left anterolateral thoracotomy extending into the right chest across the sternum (clam shell).

First step (de-branching). This step included a right carotid to right axillary artery bypass and a left

\footnotetext{
* Corresponding Author:

Ricardo G Marenchino, MD

Hospital Italiano de Buenos Aires,

Juan D. Peron 4190, C1181 ACH, Buenos Aires, Argentina

Tel.: +54 114959 5803; Fax: +54 114959 5804;

E-Mail: ricardo.marenchino@hospitalitaliano.org.ar
}

Fax +1 2037853552
E-Mail: aorta@scienceinternational.org

http://aorta.scienceinternational.org

\author{
Published by Science International Corp. \\ Accessible online at: \\ http://aorta.scienceinternational.org
}




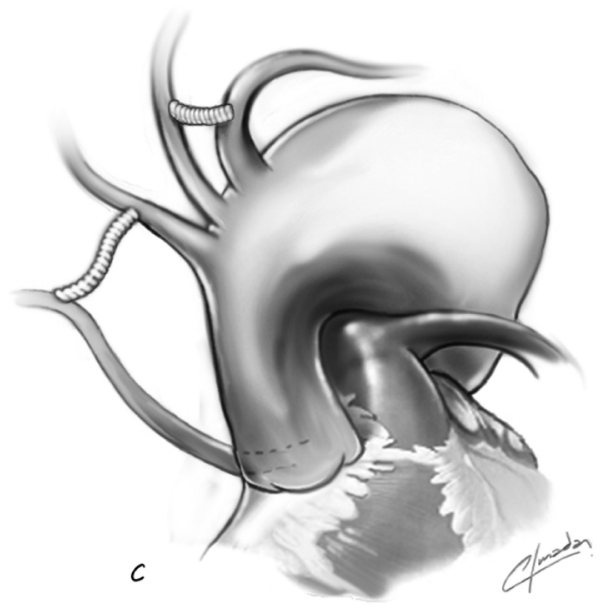

Figure 1. First Step (de-branching): Carotid-subclavian artery bypass on the left side and carotid-axillary artery bypass on the right side.

carotid to left subclavian artery bypass, using 8-mm polytetrafluoroethylene grafts (Figure 1). Then, using a thoracotomy approach, both carotid arteries were sequentially transected and anastomosed in an endto-end fashion to the two arms of a $10 \times 20 \mathrm{Y} \mathrm{graft}$ (Figure 2).

Second step (resection of aneurysm including $K D)$. CPB was established via the LSA, left femoral artery, and right atrium, and moderate hypothermia was implemented $\left(28^{\circ} \mathrm{C}\right)$. By clamping the single arm of the $Y$ graft, the head vessels and the upper body were perfused via the LSA cannula. The ascending aorta was clamped and heart was arrested. Then, the descending aorta was clamped while the abdomen was perfused via the femoral artery cannula (Figure 3 ). We resected the KD and proximal ARSA in order to resolve the esophageal compression. The ostium of LSA was oversewn.

Third step (reconstruction). The reconstruction of the aorta was performed with a \#28 Dacron graft bypass from distal ascending aorta down to the proximal descending aorta. Then, we anastomosed the single arm of the $Y$ graft in this aortic graft in an end-to side fashion (Figure 4).

Total CPB time was 90 minutes. There were no intervals between the steps.

The patient recovered very well. He was neurologically intact. His dysphagia resolved completely, and he

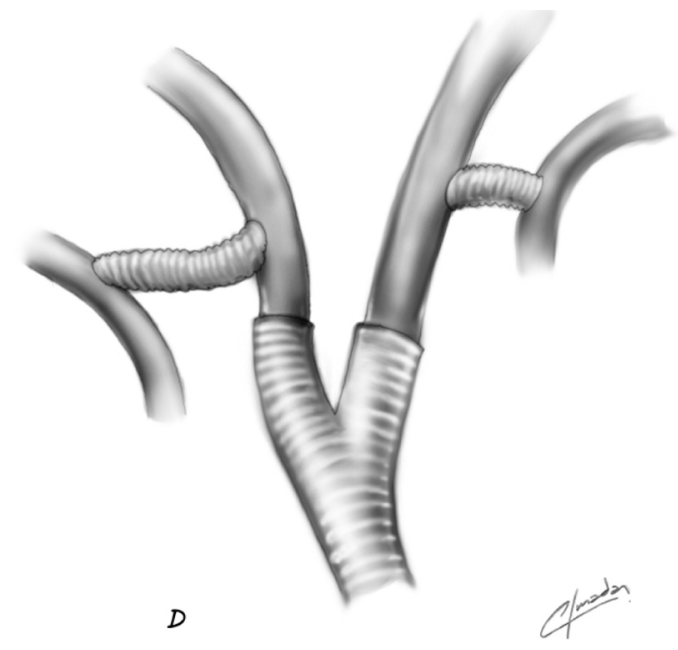

Figure 2. Carotid-carotid bypass graft with Y graft $10 \times 20 \mathrm{~mm}$.

was discharged from the hospital 3 weeks after surgery with an improving nutritional state.

\section{Discussion}

This case combines an ARSA with KD associated with a distal arch and descending thoracic aortic aneurysm in a very frail patient. The sizes of the aneurysm as well as dysphagia were both clear indications for surgery.

Considering the patient's debilitated state, a hybrid de-branching/endovascular repair was considered as an initial approach in terms of being a less traumatic intervention. However, it was ruled out for two reasons: 1) the lack of an adequate proximal landing zone for the deployment of the endovascular graft, and 2) the need for surgical resection of the diverticulum in order to resolve the dysphagia.

Although some authors have described aortic arch replacement without DHCA [1, 2], the traditional surgical approach for the treatment of this pathology requires CPB and DHCA and is associated with mortality and morbidity [3, 4]. We ruled out this option in view of our patient's malnourishment and frail condition.

We chose a procedure that was entirely surgical but avoided prolonged CPB times and DHCA. Proceeding with the de-branching component 


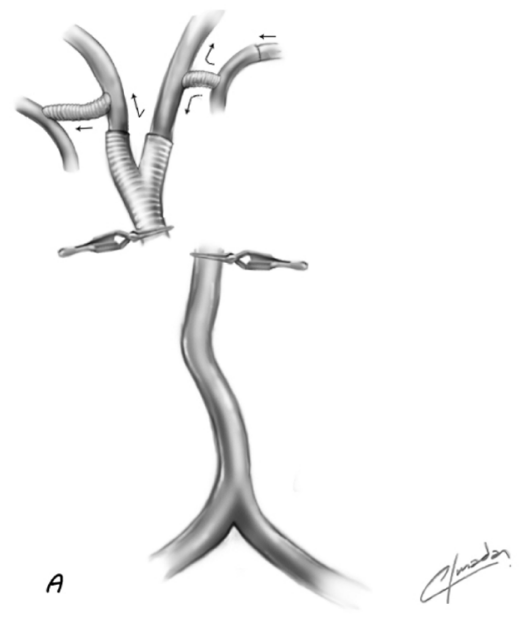

Figure 3. Cardiopulmonary bypass (CPB) was established with cannulation of the left subclavian artery (for cerebral perfusion) and left femoral artery (for systemic perfusion).

described in step 1 permitted perfusion of the brain and upper body via a cannula in LSA, avoiding the need for DHCA. CPB time was reduced considering that this step was performed off pump. Steps 2 and 3 describe a combination of standard aortic arch replacement and debranching techniques. In this case, the esophageal compression caused by the KD was significant, leading dysphagia and malnourishment. The resolution of this problem could have not been resolved with an endovascular procedure [5].

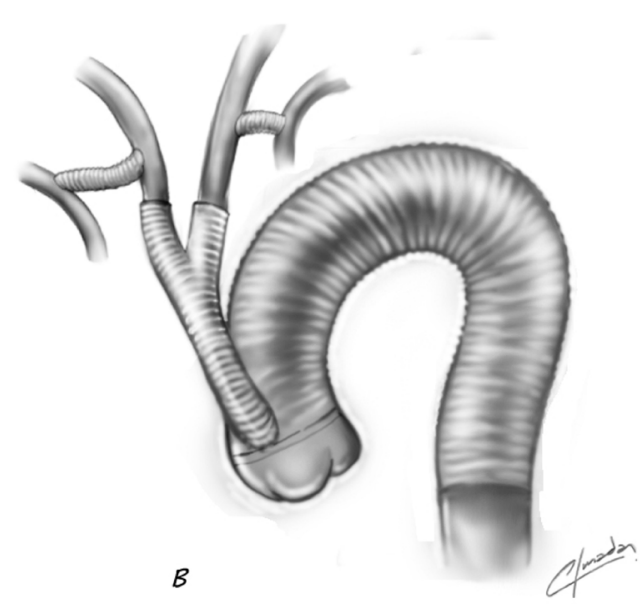

Figure 4. Aortic reconstruction with ascending to descending aorta by pass and Y-graft anastomosis in the ascending aorta.

Although we applied this technique in a patient with an ARSA and KD, we believe it could be performed in patients with arch aneurysms arch vessels anomalies.

\section{Conflict of Interest}

The authors have no conflicts of interest relevant to this publication.

\section{Comment on this Article or Ask a Question}

\section{References}

1. Ishida N, Takemura H, Shimbabukuro $\mathrm{K}$, Matsuno Y. Normothermic total arch replacement without hypothermic circulatory arrest to treat aortic distal arch aneurysm in a patient with cold agglutinin disease. Interact Cardiovasc Thorac Surg. 2011;13:432-434. DOI: 10.1510/ icvts.2011.275602

2. Matalanis G, Koirala R, Shi W, Hayward P, McCall P. Branch First aortic arch replacement with no circulatory arrest or deep hypothermia. JThorac Cardiovasc Surg. 2011;142:809815. 10.1016/j.jtcvs.2011.01.020
3. Kouchoukos N, Masetti P. Aberrant subclavian artery and Kommerell aneurysm: Surgical treatment with standard approach. J Thorac Cardiovasc Surg. 2007;133:888-892. DOI: 10.1016/j. jtcvs.2006.12.005

4. Kamiya H, Knobloch K, Lotz J, Bog A, Lichtemberg A, Hagl C, et al. Surgical treatment of aberrant right subclavian artery (arteria lusoria) using three different methods. Ann Thorac Surg. 2006;82:187-190. DOI: 10.1016/j.athoracsur.2006.02.080
5. Bosma J, Montauban A, Vahl A. Hybrid treatment of a ruptured diverticulum of Kommerell. J Endovasc Ther. 2010;17: 762-766. DOI: 10.1583/10-3174.1

Cite this article as: Marenchino RG, Domenech A. Single Stage Aortic Arch Replacement without Circulatory Arrest. AORTA (Stamford) 2016;4(1): 29-31. DOI: http://dx.doi.org/10.12945/j. aorta.2015.15.008 